\title{
The College Library and Collateral Reading Lists: The Experiences of an Historian
}

$T_{\text {HE DECISION to assemble collateral }}$ 1 reading lists for my upper division courses in modern European and English history through a personal canvass of our library stacks was prompted by several thoughts. Three years of war service had left the writer rusty in the matter of professional literature and such an inventory appeared an excellent means of refreshing my memory. Again, it seemed the most practical way of finding out what new material had been received by the library during three years' absence. Finally, and in the long run the most enduring reason, I desired to exploit more effectively for classroom purposes the actual facilities of our library.

The conviction had been growing upon me for some time that standard bibliographical guides, approved reading references in textbooks, and even our own card catalog system were not the best assurance of satisfactory collateral reading lists for my upper division courses. True it is that the bibliographies in guides and textbooks can help in building up a good reading collection over the course of years. But they will scarcely offer a true index of what books a particular library may possess at the moment. As for the card catalog system, not even the resort to subject matter headings will supply a comprehensive picture of

1 Each of the bibliographies in this article has been published in bound mimeographed form by the University of New Mexico Press, Albuquerque. library holdings in a field of study. Considerable material will still be encountered in the stacks that does not, for one reason or another, find its way into the appropriate subjects in the catalog.

That the project would demand much time and labor was fully realized. The library boasts an accumulation of one hundred and fifteen thousand volumes, a formidable array to canvass. Possible economies in time were, therefore, not overlooked. One saving was effected by collecting the data for all upper division courses on the first (and only) journey around the stacks. In my case, the courses comprised (a) Europe since 1914, (b) Europe between 1815 and 1914 , (c) Europe between 1648 and 1815 , and (d) British Empire from 1783 to the present. Another appreciable economy in time was achieved by eliminating certain stacks sections from the detailed scrutiny because of their general contents, for example, the 80o's. However, where a lead indicated profitable returns from further investigation, the more methodical procedure was applied.

The project extended over a period of eight months, being wound up during the summer when most of the books had been returned to the stacks and it was possible to make a final check of books known to be in the collection but which had not been encountered in the original canvass. To keep the bibliography up-to-date, issuing new 
editions about every four years is contemplated. Such books as the library receives in the interim will be compiled on supplementary sheets and distributed to the students.

The first day's venture into the stacks disclosed forthwith the importance of predetermining the lectures for each course. Unless the information jotted down for each item was correlated with the week-by-week classroom work, the bibliographies would emerge as nothing more than a parade of erudition. Fortunately, I had been teaching my advanced courses for several years and so held some opinions as to the topics meriting treatment and their susceptibilities for demarcation along chronological lines. My pedagogical blueprints, however, did not answer all questions. Each course produced its own peculiar challenges. Two examples are cited here to illustrate the problems that are bound to arise.

The chronological breakdown of the European bibliography for the years from I 870 to I9I 4 was made difficult by the historical developments during that period. The several domestic and foreign forces which conditioned human life at the close of the nineteenth century did not reach their individual crests at different times. Actually such forces as individualism, capitalism, overseas expansion, nationalistic and imperialistic rivalries, and existing types of international peace machinery exert their influences simultaneously upon the nascent twentieth-century social order. While the lectures can be organized to follow a sequence based upon the cause-and-effect relationship, the literature does not lend itself readily to topical subdivisions. In many instances it meant chopping up the contents of a book to a ridiculous extent and often of sapping a book of its vitality. A working compromise was finally evolved based upon what topical combinations seemed most frequently to be encountered in the literature. The bibliography for the years 1870 to 1914 was assembled under three chapter headings: (a) problems of individualism, (b) expansion overseas, and (c) international relations. What particular subjects are covered in each chapter is explained more fully in an introductory paragraph to each chapter.

\section{Temporary Solution}

The bibliography for the British Empire from 1783 to the Present likewise ran afoul the obstinacy of historical realities. The widely dispersed regions where the territories were located, the constant acquisition of new lands, the variety of political systems, and the shifts in constitutional forms were difficult to resolve under any hardand-fast headings. Then, too, considerable uncertainty still prevailed in my own mind as to the best chronological arrangement of the lectures to intercept the picture of a dynamic imperial experiment. The temporary solution here was to set up eight bibliographical chapters, some representing the dominions, others uniting colonies subject to greater mother-country control, and still others best described as embracing areas of imperial interest. The specific groupings are identified at length by an introductory paragraph to each chapter. As for the further correlation of the literature with the chronology of the lectures, the student will obviously have to be given guidance.

If the determination of the biblipgraphical chapters for each course was attended with complications, the further subdivision of the literature within each chapter had its perplexing moments. The distinctive merit of undertaking some such arrangement rested in the critical sense which might be fostered among students as to the trustworthiness of their selected reading material. At the upper division level the stu- 
dent certainly should be made aware that an author is to be judged by the informational sources he utilizes and the ability he displays in interpreting them. The adopted pattern called for four categories. The first concerned primary accounts and indicated testimony from official sources and from persons who participated in or were close witnesses of contemporary events. The second related to professional journals and comprised articles based upon the use of historical data. The third embraced studies, the yardstick being the examination of primary sources as evidenced by footnote references, listed bibliography, and the author's preparation in mastering the particular field of knowledge. The fourth covered popular literature, an admittedly arbitrary label including (a) interpretative essays, (b) instructive sketches, and (c) polemical books written from a missionary point of view. The unknown quantity in this fourth category was the amount of documentary investigation which had gone into the project.

How closely it is possible to adhere to such a pattern is another question. The line of demarcation between the several categories was not always apparent when a book was being classified. The writer will not be surprised if some books designated as primary accounts or historical studies turn out to be more properly within the realm of popular literature. Again, the phraseology of popular literature should not be taken necessarily as a reflection upon the merits of a book. The interpretative quality of its contents may be on an equal plane with that of the more documented study. Apart from such errors as may be attributed to the human equation, the bibliographies themselves provoked venturesome decisions. Perhaps two examples will serve to illustrate this plea of extenuating circumstances.

\section{Periodicals Supplement Books}

The relative fewness of the books available in our library on several British possessions left noticeable gaps in the bibliography for the British Empire from 1783 to the Present. $^{2}$ It was decided to meet the deficiency for the time being by broadening the category known as professional journals. The collection of periodicals appealing to the general public was brought into play. Great care was exercised, however, in choosing articles from this group. The name of a well-known authority affixed to an article offered some guarantee of reliability. While these men, it is true, dispensed with techniques observed by them in professional research, their ventures into the popular field were free from careless liberties with facts. Again, many articles possessed the stature of primary sources, comprising the reminiscences and memoirs of important personages. For the rest, the selections gravitate around a twilight zone, embracing impressions of special correspondents on mission and didactive accounts of responsible citizens and officials from the distant lands.

The recentness of the period considered in the course on Europe since 1914 dims somewhat the comparative value of the several categories. The traditional practice of waiting until the generation who were actors in the drama have left the stage will slow the pace of archival and family collection releases. A further aggravation is to be encountered in the case of such dictatorships as Nazi Germany, Fascist Italy, and Soviet Russia. Speaking for the years up to 1940 , the close censorship maintained in these countries makes the distinction between a substantial study and a popular account somewhat uncertain. Similarly, the inclusion of travelers' observations as pri-

\footnotetext{
2 This deficiency may exist for some time due to current difficulties in purchasing books. During the past several months, from one-third to two-thirds of orders several months, from one-third to two-thirds of order
for basic books in the above field were not obtainable.
} 
mary accounts may seem a loose interpretation of this category. Yet, failing the more official channels, the recorded experiences of foreign visitors do afford a fleeting glimpse behind the veil of censorship.

Far and beyond the tentative character of collateral reading lists dealing with current events, some comments would appear appropriate on the subject of the historian and his working bibliography. The constant flow of new documents and the rewriting of past history by each succeeding generation in the light of its own values would assure that the literature for any historical epoch and geographical area will be in a state of flux, evolving from decade to decade. If this be true, then few collateral reading lists can lay claim to a degree of definitiveness. Perhaps the main challenge at any particular moment is to group the literature according to relative validity so that the student may be conscious of the limitations governing his laboratory tools-namely, his reading material.

\section{Evaluation of Experiment}

Did the laborious combing of the stacks, book by book, achieve a better exploitation of our library holdings than resort to and reliance upon the card catalog system? Some tangible proofs that the journey was fruitful are at hand. One rich lode of books hitherto scarcely tapped consisted of university publications in the social sciences. The monographs contained therein are the dissertations of graduate students and the research projects of faculty members. Most of these studies come bound in paper covers, but our library has made them more serviceable by giving the series from each institution a more permanent binding as volumes. The gifts which come trickling in from friends of the library were another batch of dust-ridden volumes rescued from oblivion. While our library issues monthly bulletins enumerating the latest acquisitions, the full significance of many items is not always to be gleaned from the summary statements. Upon closer examination, many of these gifts represented primary accounts or standard historical works of a previous generation still meriting study. The bibliographical chapters on European expansion overseas were particularly enriched by missionary accounts. The large number of such gifts has provided a good insight into the institutional life of the Chinese, Japanese, and native African peoples.

It may likewise be inquired whether teaching experiences with the bibliographies indicate improved student reading habits. The inclusion of articles from professional journals made it possible to assign each student one such article weekly bearing upon the classroom lectures. The hope is cherished that the student will come to cultivate thereby an appetite for historical material in its most accurate and thorough stage of processing. Again, classroom time devoted to assignments for the periodic book reviews is no longer largely consumed in the mechanics of spelling out authors and titles. The students now have their own copies of a bibliography and, with the chore of taking down references no longer all-absorbing, perhaps their minds will be free to engage in critical discussions of books.

Still other possible uses of the bibliographies are envisaged, apart from immediate classroom applications. If term papers are required in a history course, the feasible topics and the related literature could be readily determined from the listings. Likewise, if advanced problem courses are to be established, the available opportunities for such concentrated readings would be more accurately gauged. Finally, the location of our university in a fairly populous center might suggest that local teachers handling social science subjects in secondary 
schools would find the bibliographies helpful in their own preparations.

\section{Benefits to Staff}

Some benefits from the project might be claimed for the library staff. Sufficient books to go around are now on hand to permit taking them out for the customary two weeks' period, thus reducing the heavy demands on reserve reading room space. Furthermore, my experiences would lead me to say that the use of two weeks' books is more conducive to sound learning than the system of reserve assignments. Whereas the latter results in readings of a restricted nature, the former makes possible fulllength studies. The information recorded in the bibliographies for each reference should mean that students can secure their reading material more easily and also that the library personnel will not be called upon so frequently to run down the call numbers of books. At the risk of overdoing the endowments which might flow, the bibliographies might serve as a guide to reference workers when answering the queries of freelance visitors whose reading desires happen to be along the lines of modern European and English history. My own services as a stack assistant, moreover, should not be lightly regarded. In ransacking the shelves, I was able to solve not a few lost book mysteries and to aid in returning misplaced books to their proper niches, exasperations which few libraries escape.

In addition, the project should not be without its lessons for our library. Since the bound volumes of professional journals and university publications are available for use only in the library, the need for concentrating them all in a single reading room can not be stressed enough. Personally, I would like to go further than this and say that since many of the books and periodicals are used by several allied departments, a divisional reading room for the social sciences and humanities might be the more desirable solution. Not only would much wasted and irksome motion be dispensed with if the student had direct access to the volumes himself, but an atmosphere of intellectual dignity might also be fostered among students who have reached the upper division level. Again, the library can take note of the deficiencies in our holdings and the direction which future purchases should take. Certainly the bibliographies will show the gaps in our collection of academic periodicals. Perhaps they may point out in what fields and in what types of material we are weak, that in one course primary accounts are too few and that in another course scholarly studies are too sparse.

By way of a final appraisal, confirmation is scarcely needed for the statement that I regained touch with the literature in my field and became acquainted with the acquisitions of the past three years. More important, may the sentiment be expressed that, whatever the actual link between potentialities and realities, the project will have contributed in some measure to the primary function of our library-namely, the dissemination of knowledge. 